\title{
Two monitored cases of sudden death outside hospital ${ }^{1}$
}

\author{
JAN POOL, KOEN KUNST, AND JAC. L. VAN WERMESKERKEN \\ From the Departments of Cardiology and General Practice, Erasmus University, Rotterdam; and the \\ Department of Cardiology, Bronovco Hospital, The Hague, The Netherlands
}

SUMMARY Two patients known to have coronary artery disease died suddenly outdoors while active. Neither had symptoms or signs of acute myocardial infarction. They were being monitored by continuous tape recording of the electrocardiogram at the time of death. In one patient the cause of death was cardiac arrest, preceded by bigeminy and multiform ventricular ectopic beats, in the other ventricular fibrillation preceded by atrial fibrillation, multiform ventricular ectopic beats, and ST depression. These observations are added to the limited reported cases in which the mechanism leading to sudden death outside the hospital is recorded.

A large proportion of the total mortality from acute coronary events occurs outside hospital (World Health Organisation, 1976). Continuous monitoring of patients with acute myocardial infarction in coronary care units has now provided information about life-threatening and lethal arrhythmias (Lown, 1966; Mogensen, 1970; DeSanctis et al., 1972). However, few cases have been documented with arrhythmias preceding and leading to sudden death outside hospital. Monitored cases are described by Bleifer et al. (1974) and Gradman et al. (1977). Baum et al. (1974) and Liberthson et al. (1974) reported arrhythmias monitored a few minutes after the acute attack.

The increased use of portable tape recorders has increased the chance of monitoring the electrocardiogram of patients who die suddenly while active in their usual occupation. Two such cases form the substance of this report, and can be added to the few cases thus far recorded.

\section{Case reports}

CASE 1

An 81-year-old man, who had had angina pectoris for many years, was referred to the clinic by his general practitioner for evaluation of his cardiac condition. Thirteen years earlier the typical pattern of an inferior infarction was found in an electrocardiogram taken for routine purposes. In recent weeks he had increasing anginal symptoms and some

${ }^{2}$ The study was supported in part by the Netherlands Foundation of Applied Research (TNO).

Received for publication 10 June 1977 dyspnoea. At physical examination there were no abnormalities. The blood pressure was $160 / 80$ $\mathrm{mmHg}$, the heart rate was regular at 84 beats/ minute. The electrocardiogram again showed the old inferior infarction, left ventricular hypertrophy, and ischaemic ST changes. No signs of fresh infarction were present. The serum levels of creatinine phosphokinase, $\alpha$-hydroxybutyric dehydrogenase, and glutamic oxaloacetic transaminase were normal. In addition, serum levels of sodium at $143 \mathrm{mmol} / \mathrm{l}$ and potassium at $3.8 \mathrm{mmol} / 1$ were normal.

After attachment of a tape recorder in order to monitor the electrocardiogram during his usual activities, the patient was sent home. About two hours later the patient collapsed while walking outdoors. The ambulance service tried cardiac massage and artificial respiration but the patient remained unconscious and died about half an hour later.

Strips of the continuous electrocardiogram (Fig. 1) show at the outset periods with bigeminy and multiform ventricular ectopic beats. A few minutes before the syncope the ventricular rhythm slowed down without recognisable $P$ waves but with normal ventricular complexes. This was followed by a cardiac arrest of about 2 minutes' duration. During the next half hour the rate varied from 40 to 80 beats per minute, while the ventricular rhythm showed bizarre complexes alternating with arrest. The last strip shows the moment the patient died in asystole. No necropsy was done.

\section{CASE 2}

This 63-year-old man was already under treatment by his cardiologist for 15 years because of angina 
$10.15 h$

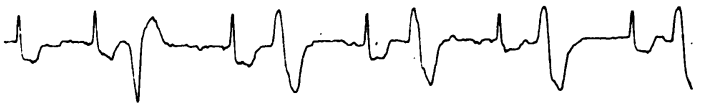

$11.12 \mathrm{~h}$

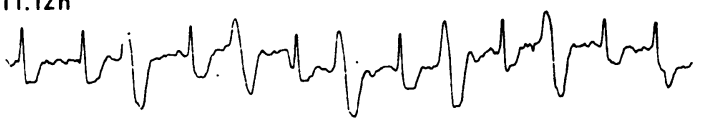

$12.32 \mathrm{~h}$

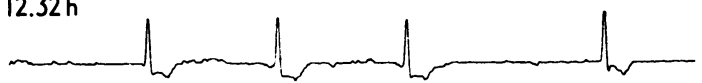

$12.32 \mathrm{~h}$

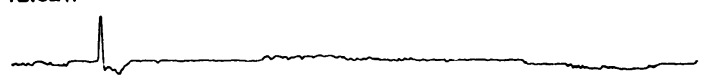

$12.33 \mathrm{~h}$

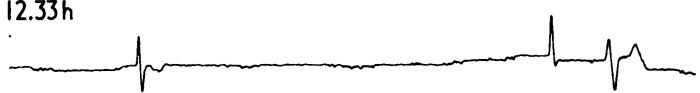

$13.08 \mathrm{~h}$

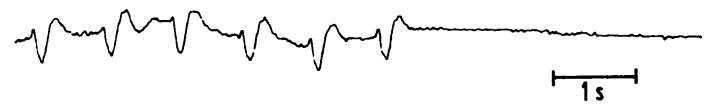

Fig. 1 Case 1. Sudden death caused by arrest. This figure shows a series of strips taken from a continuously recorded electrocardiogram, with a portable tape recorder. At $10 \cdot 15 \mathrm{~h}$ a period of bigeminy and multiform ventricular beats; at $11.13 \mathrm{~h}$ again a period of bigeminy; at $12.32 \mathrm{~h}$ decrease of the heart rate followed by an arrest of about 2 minutes. At 13.08 h final arrest.

pectoris and hypertension. Twelve years ago he had had a slight myocardial infarction. Six months previously he suddenly collapsed. On the electrocardiogram then taken atrial fibrillation was present. The patient was treated with anticoagulants, digoxin, and isosorbide dinitrate. In recent days symptoms of dizziness and syncope returned and he was referred to us. The electrocardiogram again showed atrial fibrillation and an old anterior myocardial infarction but no signs of ischaemia or fresh infarction. No laboratory tests were done. Since the patient felt well he was sent home with a tape recorder for monitoring his electrocardiogram. In the afternoon without warning he died suddenly while washing his car. The ambulant electrocardiogram (Fig. 2) showed atrial fibrillation with some multiform ventricular ectopic beats. A few minutes before death the ventricular rate increased, ST depression appeared, and after a ventricular ectopic beat ventricular flutter started. It finally changed into ventricular fibrillation just before death. No $\stackrel{\vec{C}}{\mathrm{C}}$ necropsy was done.
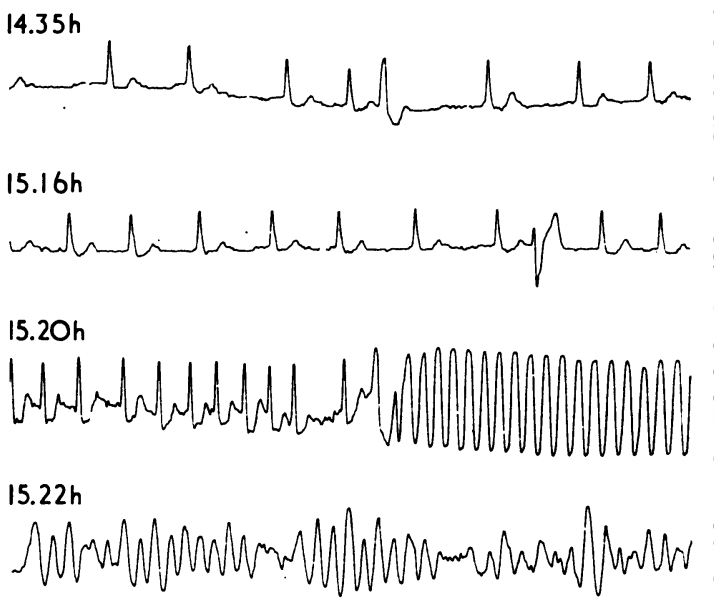

$15.3 \mathrm{lh}$

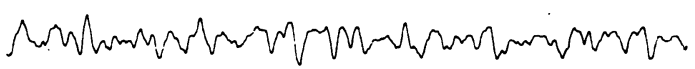

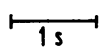

Fig. 2 Case 2. Sudden death caused by ventricular fibrillation. This figure shows a series of strips taken from a continuous electrocardiogram recorded with a portable tape recorder. At $14 \cdot 35 \mathrm{~h}$ and $15 \cdot 16 \mathrm{~h}$ atrial fibrillation with multiform ventricular ectopic beats; at $15 \cdot 20 \mathrm{~h}$ increased heart rate, ST depression, and a ventricular ectopic beat followed by ventricular flutter; $15.22 \mathrm{~h}$ alternating ventricular flutter and ventricular fibrillation; at $15.31 \mathrm{~h}$ rough and at $15.36 \mathrm{~h}$ fine ventricular fibrillation.

\section{Discussion}

Two cases of primary sudden death are presented. History and physical findings were negative, while N biochemical and electrocardiographic signs of an $\circlearrowleft$ acute myocardial infarction were absent, though 2 both patients had had angina pectoris for many years and had had myocardial infarcts years ago. $\stackrel{\Phi}{\rightarrow}$ This finding is in agreement with the results of Baum et al. (1974) who reported that in many $(50.5 \%)$ resuscitated cases of primary out-of- $\mathbb{\mathbb { D }}$ hospital ventricular fibrillation no acute myocardial $\underset{\mathbb{D}}{\vec{D}}$ infarction could be shown. Nevertheless, 94 per cent of their patients who were subsequently studied by coronary arteriograms showed severe coronary 
artery disease. In the first reported case the apparent cause of death is cardiac arrest and not ventricular fibrillation. Premonitory symptoms of dizziness and syncope were missing and the first clinical attack proved lethal. On the other hand the arrest was preceded by warning arrhythmias like bigeminy and multiform ventricular ectopics, which could have been harbingers of imminent ventricular fibrillation. In fact asystole took place. Liberthson et al. (1974) reported that in 28 per cent of cases of prehospital sudden coronary death monitored by fire rescue squads, terminal rhythms other than ventricular fibrillation, such as bradycardia and asystole, were found.

The second case is a typical example of primary ventricular fibrillation preceded by warning arrhythmias in a patient with known coronary atherosclerotic heart disease. The finding of atrial fibrillation probably reassured the physician in the interpretation of the syncope of his patient. This experience indicates that ambulatory electrocardiography may improve diagnostic accuracy of the physician in such patients.

Surprisingly, few cases of sudden death with rhythm monitoring outside hospital are reported. Gradman et al. (1977) reported a case of primary ventricular fibrillation quite similar to case 2 . Warning arrhythmias, tachycardia, and ST depression preceded the acute attack. Bleifer et al. (1974) described a case of ventricular fibrillation in a patient with a symptomless acute myocardial infarction.

Hinkle (1978) saw a case of primary ventricular fibrillation also preceded by warning arrhythmias.

The now widespread and still increasing use of ambulant monitoring and the reported predictive value of arrhythmias (Oliver et al., 1974; Ryan et al., 1975; Van Durme, 1975; Moss et al., 1975) should enhance the chance of finding more such cases. It is hoped that pooling of this type of information will increase the knowledge about lethal arrhythmias and its prodromal warnings in order to improve our management of secondary prevention.

\section{References}

Baum, R. S., Alvarez, H., III, and Cobb, L. A. (1974). Survival after resuscitation from out-of-hospital ventricular fibrillation. Circulation, 50, 1231-1235.

Bleifer, S. B., Bleifer, D. J., Hansmann, D. R., Sheppard, J. J., and Karpman, H. L. (1974). Diagnosis of occult arrhythmias by Holter electrocardiography. Progress in Cardiovascular Diseases, 16, 569-599.

DeSanctis, R. W., Block, P., and Hutter, A. M. (1972). Tachyarrhythmias in acute myocardial infarction. Circulation, 45, 681-702.

Gradman, A. H., Bell, P. A., and DeBusk, R. F. (1977). Sudden death during ambulatory monitoring; clinical and electrocardiographic correlations. Report of a case. Circulation, 55, 210-211.

Hinkle, L. E. (1978). Personal communication. American fournal of Cardiology, accepted for publication.

Liberthson, R. R., Nagel, E. L., Hirschman, J. C., Nussenfeld, S. R., Blackbourne, B. D., and Davis, J. H. (1974). Pathophysiologic observations in prehospital ventricular fibrillation and sudden cardiac death. Circulation, 49, 790-798.

Lown, B. (1966). The Current Status of Coronary Care. The Charles Press, Philadelphia.

Mogensen, L. (1970). Ventricular tachyarrhythmias and lignocaine prophylaxis in acute myocardial infarction. A clinical and therapeutic study. Acta Medica Scandinavica, Suppl. 513.

Moss, A. J., DeCamilla, J., Mietlowski, W., Greene, W. A., Goldstein, S., and Locksley, R. (1975). Prognostic grading, and significance of ventricular premature beats after recovery from myocardial infarction. Circulation, 52-III, 204-210.

Oliver, G. C., Kleiger, R. E., Krone, R. J., Martin, T. F., Miller, J. P., Nolle, F. M., and Cox, J. R., Jr. (1974). In Conference on Computers in Cardiology, pp. 43-46. National Institutes of Health, IEEE Computer Society and European Society of Cardiology, Maryland.

Ryan, M., Lown, B., and Horn, H. (1975). Comparison of ventricular ectopic activity during 24-hour monitoring and exercise testing in patients with coronary heart disease. New England fournal of Medicine, 292, 224-229.

Van Durme, J. P. (1975). Studie van Prognose en Behandeling van Ritmestoornissen na de Akute Fase van het Myokardinfarct. Thesis, Gent.

World Health Organisation Regional Office for Europe (1976). Myocardial Infarction Community Registers. Public Health in Europe, 5, Copenhagen.

Requests for reprints to Dr Jan Pool, Thoraxcenter, Erasmus University, P.O. Box 1738, Rotterdam, The Netherlands. 